\title{
SINTESIS DAN KARAKTERISASI CANGKANG KAPSUL KERAS DARI GELATIN TULANG IKAN LELE DUMBO (CLARIAS GARIEPINUS)
}

\author{
Triyani Sumiati*1, Devi Ratnasari ${ }^{2}$, Siti Rosidah hanapiah $^{3}$, Ari Setiadji ${ }^{4}$ \\ ${ }^{123}$ Program Studi S1 Farmasi, Sekolah Tinggi Teknologi Industri dan Farmasi, Bogor \\ ${ }^{4}$ PT. Kapsulindo Nusantara \\ *Korespondensi : triyanisumiati@gmail.com
}

\begin{abstract}
ABSTRAK
Kapsul adalah bentuk sediaan obat terbungkus cangkang kapsul keras atau lunak. Cangkang kapsul dibuat dari gelatin dengan atau tanpa zat tambahan lain. Gelatin merupakan suatu zat yang diperoleh dari hidrolisa parsial dari kulit atau tulang hewan. Sumber gelatin yang dapat digunakan sebagai bahan dasar pembentuk kapsul cangkang keras diantaranya tulang atau kulit dari sapi, babi, ikan. Ikan lele dapat digunakan sebagai bahan dasar untuk pembuatan gelatin. Penelitian ini bertujuan untuk membuat dan mengevaluasi karakteristik kapsul cangkang keras dari gelatin yang dibuat dari gelatin tulang ikan lele dumbo (Clarias garepinus). Proses pembuatan gelatin dilakukan dengan menggunakan cara asam. Hasil pengujian gelatin menunjukan nilai $\mathrm{pH}$ gelatin 4,85, kadar air 13,5 $\%$, viskositas 180-190 Cps, kadar abu 3,2\% dan kekuatan gel $150 \mathrm{~g} / \mathrm{cm}^{2}$. Gelatin yang dihasilkan kemudian digunakan untuk pembuatan cangkang kapsul keras yang dibedakan menjadi 2 formula dengan memvariasikan jumlah gelatin yang digunakan (Formula $\mathrm{I}=25 \mathrm{~g}$ dan formula $\mathrm{II}=35 \mathrm{~g}$ gelatin). Evaluasi terhadap karakteristik cangkang kapsul yang meliputi dimensi cangkang kapsul, pengukuran volume cangkang kapsul, waktu hancur dalam air dan larutan asam, kadar air dan kerapuhan. Hasil pengujian karakteristik yang tidak memenuhi persyaratan pada formula I adalah penetapan kadar air dan kerapuhan, sedangkan pada formula II hanya pada penetapan kadar air.
\end{abstract}

\section{Kata kunci : Cangkang Kapsul Keras, Gelatin, Ikan Lele Dumbo (Clarias Gariepinus)}

\begin{abstract}
Capsule is form of drug preparations wrapped in hard or soft. Capsule shell made from gelatin with or without additives. Gelatin is a substance which obtained from partial hydrolysis of the skin or animal bone. Gelatin source which can be used as a base material to forms a hard shell capsule that is bone or skin of cow, pig, and fish. Catfish can be used as the basic ingredient to make a gelatin. This research was intended to create and evaluate the characteristics of hard shell capsule which made from the gelatin of catfish dumbo (Clarias garepinus) bones. The process of making gelatin was done with use the acid method. The result of gelatin test showed that gelatin's $\mathrm{pH} 4.85$, water content $13,5 \%$, viscosity $180-190 \mathrm{Cps}$, ash content $3,2 \%$ and gel strength $150 \mathrm{~g} / \mathrm{cm} 2$. The gelatin which have been produced then used to make a hard capsule shell which was divided into 2 formulas by varying the amount of gelatin used (Formula $\mathrm{I}=25 \mathrm{~g}$ and formula $\mathrm{II}=35 \mathrm{~g}$ of gelatin). Evaluation of characteristics of the capsule shell which includes the dimensions of the capsule shell, volume the capsule shell, the time of disintegration in water and acid liquid, moisture content and friability. The result of characteristic test which not conforms the requirement of formula I is the determination of moisture content and friability, while on formula II only moisture content.
\end{abstract}

\section{.Keywords: Hard Capsule Shell, Gelatin, Dumbo Catfish (Clarias Gariepinu)}




\section{PENDAHULUAN}

Kapsul merupakan sediaan paling serbaguna yang dapat digunakan sebagai pembawa untuk obat berbentuk serbuk, granul maupun cairan. Materi pembentuk cangkang kapsul adalah gelatin karena bersifat edible (mudah dimakan) dan larut.[1] Gelatin merupakan bahan baku yang digunakan dalam industri pangan, farmasi, kosmetika, fotografi dan beberapa industri lainnya. Sumber utama gelatin adalah dari tulang dan kulit sapi serta babi, produksi gelatin dari bahan baku kulit babi mencapai $44 \%$, kulit sapi $28 \%$, tulang sapi $27 \%$ dan porsi lainnya $1 \%$, dengan total produksi dunia mencapai 326.000 ton.

Penggunaan gelatin dari tulang sapi untuk pembuatan cangkang kapsul maupun untuk produk-produk pangan lainnya dapat menimbulkan kekhawatiran masyarakat terkait dengan adanya isu penyakit sapi gila ( $m a d$ cow disease)[2] dan juga adanya beberapa keterbatasan pada aspek religi, dimana masyarakat Yahudi dan Islam memiliki pantangan untuk mengonsumsi bahan-bahan dari babi, sedangkan masyarakat Hindu tidak mengonsumsi bahan-bahan dari sapi. [3] Mengingat hal tersebut maka perlu di cari alternatif sumber gelatin baru. Gelatin yang diproduksi dari hasil samping ikan merupakan alternatif potensial dibanding gelatin dari mamalia. [4]

Jumlah produksi ikan lele di Indonesia yang terus meningkat menyebabkan limbah tulang ikan lele semakin banyak. Pada tahun 2013 jumlah produksi ikan lele sebesar 543.461 ton, jumlah ini lebih besar dibandingkan dengan produksi ikan gurame yang hanya sebesar 94.605 dan produksi ikan lainnya sebesar 352.795. [5]

Pada penelitian ini akan dilakukan optimasi konsentrasi gelatin dari tulang ikan lele dumbo sebagai bahan dasar pembuatan cangkang kapsul. Metode yang dipilih untuk pembuatan gelatinnya adalah metode asam (tipe A) karena tulang ikan memiliki tekstur tulang muda.

\section{METODE PENELITIAN}

Waktu: Penelitian ini dilakukan di Laboratorium Farmasi Sekolah Tinggi Teknologi Industri dan Farmasi Bogor di Jln. Parung Aleng, Ds. Cikeas Kab. Bogor 16710. dan di PT. Kapsulindo Indonesia Jl. Pancasila
No.1, Cicadas, Gn. Putri, Bogor, Jawa Barat 16963. Penelitian ini dilaksanakan dari bulan Mei hingga bulan September 2017.

Bahan: Bahan yang digunakan pada penelitian ini adalah limbah tulang ikan lele dumbo yang diperoleh dari Balai Besar Perikanan Air Tawar (BBPAT) Sukabumi dan dari petani ikan lele, aquadest, HCL 37\% (Merck), gelatin tulang ikan lele, gliserin (Brataco), pewarna (Tartazin).

Alat: Alat yang digunakan adalah neraca analitik (AND HF-TE1502S), alat gelas (PYREX), oven (Blue M), cawan porselen, $\mathrm{pH}$ meter (METROHM), pH Universal (Merck), Brookfield viscometer, disintegration tester (VEEGO), Bloom Gelometer, Hot plate (Thermo), cawan porselen, caliper digital (Mituyoto), dial indicator (Mituyoto), tanur (Neycraft), waterbath (Julabo 20B), pencetak kapsul ukuran no 2, kompor gas (RINNAI), panci rebus, pisau (Tupperware), lemari pendingin (SANYO).

\section{METODE}

\section{Pembuatan Gelatin}

Penelitian ini di mulai dengan persiapan bahan baku yaitu proses deagreasing, tulang ikan lele dumbo yang sudah dipotong-potong ukuran 2-4 cm dimasukan ke dalam air panas dengan suhu $90^{\circ} \mathrm{C}$ selama 10 menit untuk menghilangkan sisa daging yang menempel pada tulang ikan. Selanjutnya proses demineralisasi dilakukan dengan cara merendam tulang ikan lele yang sudah dipotong-potong menggunakan $\mathrm{HCl}$ 3,35\% dengan perbandingan 1:6 (b : v) selama \pm 8 jam. Hasil dari demineralisasi disebut dengan ossein (Tulang lunak), Ossein yang didapatkan kemudian di cuci dengan air mengalir, kemudian diekstraksi menggunakan pelarut akuades perbandingan 1:5 pada suhu bertingkat pada suhu $70^{\circ} \mathrm{C}, 80^{\circ} \mathrm{C}$ dan $90^{\circ} \mathrm{C}$ selama \pm 6 jam. Filtrat yang di peroleh disaring dengan menggunakan kain saring kemudian di pekatkan menggunakan hot plate.

Larutan yang sudah pekat kemudian disimpan dalam lemari pendingin pada suhu $10^{\circ} \mathrm{C}-15^{\circ} \mathrm{C}$ hingga menjadi gel \pm 3 jam, gel yang sudah terbentuk digunting untuk memperkecil ukuran gelatin dan simpan kembali di dalam lemari pendingin selama 5 hari hingga potongan gelatin membentuk serbuk gelatin. 


\section{Pengujian Gelatin \\ Pengujian pH}

Penetapan $\mathrm{pH}$ mengacu pada prosedur tetap PT. Kapsulindo Nusantara, 2013. Sebanyak $1,5 \%(\mathrm{~b} / \mathrm{v})$ gelatin ditimbang dan dilarutkan kedalam $50 \mathrm{ml}$ pada suhu $50^{\circ} \mathrm{C}$ kemudian dinginkan suhu $25^{\circ} \mathrm{C}$. kemudian diukur pHnya pada suhu kamar $\left(20^{\circ} \mathrm{C}-25^{\circ} \mathrm{C}\right)$ dengan menggunakan alat $\mathrm{pH}$ meter.

\section{Pengujian Kadar Air}

Kadar air dilakukan berdasarkan perbedaan bobot sampel sebelum dan sesudah pengeringan. Langkah pertama panaskan cawan kosong keadalam oven pada suhu $100-105^{\circ} \mathrm{C}$ selama 1 jam, kemudian didinginkan dalam desikator selama 15 menit dan ditimbang sampai didapat bobot konstan. Gelatin di timbang sebanyak $5 \mathrm{~g}$ dalam cawan yang bobotnya telah konstan, kemudian dikeringkan dalam oven pada suhu $100-105^{\circ} \mathrm{C}$ selama 17 jam. Dinginkan dalam desikator selama 1 jam, setelah dingin kemudian ditimbang kembali. Ulangi pemanasan hingga mendapatkan bobot yang konstan. [6]

Kadar air $(\%)=\frac{m 1-m 2}{m 1-m 0} \times 100 \%$

Keterangan:

$\mathrm{m} 0$ =Bobot wadah kosong

$\mathrm{m} 1$ =Bobot wadah + sampel sebelum pengeringan

$\mathrm{m} 2$ =Bobot wadah + sampel yang sudah dipanaskan

\section{Pengujian Kadar Abu}

Dipanaskan cawan pada tanur dengan temperatur $550^{\circ} \mathrm{C}$ selama 30 menit, kemudian didinginkan dalam desikator selama 30 menit, dan ditimbang sampai bobot cawannya konstan. diulangi beberapa kali hingga bobotnya konstan Ditimbang $1,5 \mathrm{~g}-2 \mathrm{~g}$ gelatin dalam cawan porselen yang bobotnya sudah konstan. Gelatin dalam cawan dipanaskan hingga seluruhnya menjadi arang (Pemanasan dilakukan diatas penangas bunsen didalam lemari asam. Cawan yang telah dipanaskan dipindahkan kedalam tanur dan teruskan pemanasan pada temperatur $550^{\circ} \mathrm{C}$, sampai menjadi abu seluruhnya (warna abu menjadi warna putih). Cawan didalam tanur diangkat dan didinginkan dalam desikator selama 30 menit, setelah dingin ditimbang. [6]

Bobot $a b u=($ Bobot cawan + abu $)-$ bobot cawan kosong
Kadar abu $=\frac{\text { Bobot abu }}{\text { Bobot sampel }} \times 100 \%$

\section{Pengujian Viskositas}

Ditimbang 6,67 gelatin dan dilarutkan dalam air sebanyak $100 \mathrm{~mL}$. kemudian panaskan pada suhu $60^{\circ} \mathrm{C}$ pemanasan dilakukan karena gelatin tidak larut dan akanmengembang pada air dingin sedangkan gelatin larut dengan pemanasan, pengukuran dilakukan dengan menggunakan alat viscometer Brookfield. Nilai viskositas dinyatakan dalam satuan centipoise (cPs). [7]

\section{Pengujian Kekuatan gel (Gel Strength)}

Gelatin ditimbang 7,5 g ditambahkan 105 $\mathrm{mL}$ aquadest dalam botol pengujian kekuatan gel, tutup botol menggunakan alumunium foil, larutkan sampel pada suhu $50^{\circ} \mathrm{C}$ sampai larut. Sampel diletakan pada child batch suhu $10^{\circ} \mathrm{C}$ selama 4 jam, kemudian diukur dengan mennggunakan alat gelometer. [6]

\section{Pencetakan Cangkang Kapsul Keras}

Pada pembuatan cangkang kapsul ini dibedakan atas 2 formulasi. Perbedaan tersebut berdasarkan jumlah gelatin yang ditambahkan yaitu $25 \mathrm{~g}$ dan $35 \mathrm{~g}$. Formulasi ini mengacu pada standar formulasi pembuatan cangkang kapsul yang [8] dengan adanya modifikasi.

\section{Tabel 1. Formulasi bahan pembentuk cangkang kapsul keras}

\begin{tabular}{cccc}
\hline \multirow{2}{*}{ Bahan } & Fungsi & $\begin{array}{c}\text { Formula } \\
\text { Nerbuk }\end{array}$ & $\begin{array}{c}\text { Formula } \\
\text { Pembent }\end{array}$ \\
\cline { 3 - 4 } & Jumlah & Jumlah \\
\hline $\begin{array}{c}\text { Gelatin } \\
\text { Gliseri } \\
\text { n film }\end{array}$ & $\begin{array}{c}\text { Plasticiz } \\
\text { er }\end{array}$ & $0,5 \mathrm{~mL}$ & $0,5 \mathrm{~mL}$ \\
$\begin{array}{c}\text { Tartraz } \\
\text { in }\end{array}$ & $\begin{array}{c}\text { Pewarna } \\
\text { Air }\end{array}$ & $0,25 \mathrm{~mL}$ & $0,25 \mathrm{~mL}$ \\
\hline
\end{tabular}

Proses pembuatan cangkang kapsul dilakukan dengan menimbang untuk masingmasing formula sebanyak 25 gram dan 35 gram gelatin tulang ikan lele dumbo dan dimasukan kedalam gelas piala $100 \mathrm{~mL}$, dan ditambahkan pelarut aquadest 1:2. Campuran tersebut dipanaskan pada suhu $50^{\circ} \mathrm{C}$ hingga gelatin benar-benar larut, pada larutan tersebut ditambahkan sebanyak $0,5 \mathrm{~mL}$ gliserin dan 0,25 $\mathrm{mL}$ pewarna tartazin di masukan kedalam larutan. Kemudian diaduk hingga homogen. 


\section{HASIL DAN PEMBAHASAN}

\section{Pengukuran Dimensi Cangkang Kapsul}

Panjang dan diameter cangkang kapsul diukur menggunakan jangka sorong. Ketebalan cangkang kapsul diukur menggunakan alat pengukur ketebalan kapsul. Pengukuran berat cangkang kapsul ditimbang dengan neraca analitik. Pengamatan warna cangkang kapsul diamati secara visual

\section{Pengukuran Volume Cangkang Kapsul}

Pengukuran volume cangkang kapsul dilakukan dengan menggunakan spuit dimana cangkang kapsul diisi dengan air sampai penuh, dan dilihat berapa $\mathrm{mL}$ air yang berkurang pada spuit.

\section{Pengujian Waktu Hancur Dalam Air}

Analisis waktu hancur kapsul dilakukan dengan menggunakan alat disintegration tester. Sebanyak satu kapsul dimasukan pada masingmasing tabung dari keranjang, kemudian satu cakram dimasukan pada setiap tabung, kemudian alat dijalankan. Rangkaian keranjang bergerak secara vertikal sepanjang sumbunya tanpa gerakan horizontal yang berarti atau gerakan sumbu dari posisi vertikalnya. Air yang digunakan memiliki suhu $37^{\circ} \mathrm{C}$ sebagai media, kecuali dinyatakan lain waktu yang diperlukan untuk menghancurkan kelima kapsul tidak boleh lebih dari 15 menit [9]

\section{Pengujian Kadar Air}

Cangkang kapsul Komersial (Cangkang Kapsul di pasaran) harus memiliki kadar air antara 13\% sampai degan 16\%. [6] Penentuannya adalah dengan cara keringkan alumunium dish pada oven suhu $105^{\circ} \mathrm{C}$ selama 1 jam, kemudian didinginkan dalam desikator selama 15 menit dan ditimbang sampai didapat bobot konstan. 5 gram kapsul ditimbang dalam alumunium dish bobotnya telah konstan, selanjutnya dikeringkan dalam oven pada suhu $100-105^{\circ} \mathrm{C}$ selama 17 jam. Cawan yang sudah dipanaskan didinginkan kembali dalam desikator selama 30 menit, setelah dingin cawan kemudian ditimbang kembali. Ulangi pemanasan hingga mendapatkan bobot yang konstan. [6]

Kadar air $(\%)=\frac{\mathrm{m} 1-\mathrm{m} 2}{\mathrm{~m} 1-\mathrm{m} 0} \times 100 \%$

Keterangan:

$\mathrm{m} 0=$ Bobot wadah kosong

$\mathrm{m} 1=$ Bobot wadah + sampel sebelum pengeringan

$\mathrm{m} 2$ =Bobot wadah + sampel yang sudah dipanaskan

\section{Pengujian Waktu Hancur Dalam Larutan Asam}

Analisis kelarutan dalam larutan asam hampir sama dengan analisis kelarutan dalam air menggunakan alat disintegration tester. Media yang digunakan adalah $\mathrm{HCl} 0,1 \mathrm{~N}$ dengan suhu $37^{\circ} \mathrm{C}$ sehingga $\mathrm{pH}$ cairan mendekati komposisi cairan lambung. Cangkang kapsul Komersial (Cangkang Kapsul di pasaran) harus larut dalam larutan asam dalam waktu kurang dari 5 menit. [10]

\section{Pengujian Kerapuhan}

Pada uji ini, cangkang kapsul dijatuhkan beban $50 \mathrm{~g}$ dari ketinggian $10 \mathrm{~cm}$ dimana beban $50 \mathrm{~g}$ ini di anggap sebagai tekanan yang terjadi saat membuka kemasan kapsul. Kapsul dikatakan rapuh apabila setelah dijatuhkan beban, cangkang kapsul retak atau pecah. Kapsul akan rapuh jika kada airnya rendah. Sebaliknya jika kadar airnya tingi, kapsul cenderung akan melunak. [11]

\section{HASIL DAN PEMBAHASAN Hasil Pengujian Gelatin}

Tabel 2. Hasil pengujian gelatin

\begin{tabular}{lcccc}
\hline No & Pengujian & $\begin{array}{c}\text { Gelatin tulang } \\
\text { ikan lele } \\
\text { (Clarias } \\
\text { gariepinus) }\end{array}$ & $\begin{array}{c}\text { Persyaratan yang } \\
\text { ditetapkan [12] }\end{array}$ & SNI No. 06-3735a [13] \\
\hline $\mathbf{1 .}$ & $\mathrm{pH}$ & 4,85 & 5,9 & $4,6-6,5$ \\
$\mathbf{2 .}$ & Kadar air & $13,5 \%$ & $11 \%$ & Maks 16\% \\
$\mathbf{3 .}$ & Kadar abu & $3,2 \%$ & $1,4 \%$ & Maks 3,25\% \\
$\mathbf{4 .}$ & Viskositas & $180-190 \mathrm{Cps}$ & $380 \mathrm{Cps}$ & - \\
$\mathbf{5 .}$ & Kekuatan gel & $150 \mathrm{~g} / \mathrm{cm}^{2}$ & $202 \mathrm{~g} / \mathrm{cm}^{2}$ & - \\
\hline & & & \\
\hline
\end{tabular}


Pengujian nilai $\mathrm{pH}$ dilakukan untuk mengetahui derajat keasaman pada gelatin. Nilai $\mathrm{pH}$ akan mempengaruhi kualitas gelatin diantaranya kekuatan gel dan viskositas gel, nilai $\mathrm{pH}$ gelatin tidak mempengaruhi pembuatan cangkang kapsul karena pada pengujiannya hanya tertuju untuk mengetahui nilai $\mathrm{pH}$ [14] dalam gelatin Menurut literature [12] $\mathrm{pH}$ gelatin tulang ikan adalah 5,9 atau mendekati netral. Nilai $\mathrm{pH}$ gelatin yang diperoleh dari penelitian ini adalah sebesar 4,85 . Nilai $\mathrm{pH}$ yang rendah tersebut diduga disebabkan karena proses pencucian yang kurang optimal, sehingga pada proses pencucian perlu dioptimalkan kembali.

Kandungan air dalam suatu bahan dapat menentukan tekstur dan masa simpan [15] Berdasarkan hasil pengukuran kadar air pada gelatin tulang ikan lele dumbo diperoleh jumlah kadar air sebesar $13,5 \%$. Nilai ini lebih tinggi jika dibandingkan dengan literatur yaitu sebesar $11 \%$. Perbedaan kadar ini diduga karena waktu pemekatan gelatin yang kurang.

Kadar abu dalam pengujian gelatin menunjukan banyaknya mineral yang terkandung dan menunjukan kemurnian dari gelatin. Pengujian kadar abu pada gelatin tulang ikan lele dumbo didapatkan hasil 3,2\% sedangkan jika dibandingkan dengan literatur kadar abu untuk gelatin tulang ikan lele dumbo adalah $1,4 \%$. Nilai kadar abu yang tinggi dipengaruhi oleh lamanya proses demineralisasi, semakin banyak garam mineral yang hilang akan menyebabkan nilai kadar abu rendah yang berarti gelatin semakin murni.

Pengujian viskositas pada gelatin tulang ikan lele dumbo didapatkan hasil $180-190 \mathrm{Cps}$ sedangkan pada literatur untuk gelatin tulang ikan viskositasnya adalah 380 Cps. Nilai viskositas gelatin yang lebih rendah dari literatur disebabkan karena penggunaan suhu ektraksi terlalu tinggi yang mengakibatkan terjadi hidrolisis lanjutan sehingga struktur rantai asam amino semakin terbuka sehingga rantai tersebut semakin pendek dan menyebabkan berat molekulnya menjadi semakin rendah dengan demikian nilai viskositas gelatin akan menurun.[16]

Kekuatan gel (Bloom strength) didefinisikan sebagai besarnya gaya yang diperlukan oleh probe untuk menekan gel setinggi $4 \mathrm{~mm}$ sampai gel pecah. Bloom strength ini merupakan sifat fisik yang penting dari gelatin, karena gelatin dapat berubah dari sol menjadi gel maupun sebaliknya yang disebut dengan sifat reversible. Berdasarkan hasil percobaan kekuatan gel dengan menggunakan alat gelometer kekuatan gel yang didapatkan adalah $150 \mathrm{~g} / \mathrm{cm}^{2}$ namun pada literatur kekuatan gel untuk gelatin tulang ikan adalah $202 \mathrm{~g} / \mathrm{cm}^{2}$. Kekuatan gel dapat dipengaruhi oleh 2 faktor, faktor pertama adalah suhu ekstraksi dimana semakin rendah suhu ekstraksi maka nilai kekuatan gel akan semakin tinggi. Faktor kedua adalah konsentrasi larutan asam (demineralisasi), larutan yang terlalu pekat akan merusak struktur gelatin sehingga gel tidak terbentuk. [17] Pada penelitian ini pH gelatin yang didapatkan adalah 4,85 sedikit asam dari persyaratan yang diteteapkan sehingga menyebabkan kekuatan gelnya rendah

\section{Hasil Pengujian Cangkang Kapsul Keras}

Tabel. 3 Hasil pengujian cangkang kapsul

\begin{tabular}{|c|c|c|c|c|c|}
\hline \multirow[t]{2}{*}{ No } & \multicolumn{2}{|c|}{ Pengujian } & \multicolumn{2}{|c|}{$\begin{array}{c}\text { Kapsul gelatin tulang ikan lele dumbo } \\
\text { (Clarias gariepinus) }\end{array}$} & \multirow[t]{2}{*}{$\begin{array}{c}\text { Persyaratan yang } \\
\text { ditetapkan [6] }\end{array}$} \\
\hline & & & Formula 1 & Formula 2 & \\
\hline \multirow[t]{2}{*}{1.} & Panjang & Badan & $14,25-17,10 \mathrm{~mm}$ & $14,50-18,40 \mathrm{~mm}$ & $14,80 \mathrm{~mm}-15.70 \mathrm{~mm}$ \\
\hline & & Tutup & 08.80-09,60 mm & $07.80-09,10 \mathrm{~mm}$ & $08,50 \mathrm{~mm}-09,40 \mathrm{~mm}$ \\
\hline \multirow[t]{2}{*}{2.} & Diameter & Badan & $6,05 \mathrm{~mm}$ & $6,07 \mathrm{~mm}$ & $6,045 \mathrm{~mm} \pm 0,127 \mathrm{~mm}$ \\
\hline & & Tutup & $6,4 \mathrm{~mm}$ & $6,5 \mathrm{~mm}$ & $6,325 \mathrm{~mm} \pm 0,203 \mathrm{~mm}$ \\
\hline \multirow[t]{2}{*}{3.} & Ketebalan & Badan & $0,15-0,20 \mathrm{~mm}$ & $0,15-0,19 \mathrm{~mm}$ & $0,18 \mathrm{~mm}-0,20 \mathrm{~mm}$ \\
\hline & & Tutup & $0,17-0,18 \mathrm{~mm}$ & $0,18-0,20 \mathrm{~mm}$ & $0,19 \mathrm{~mm}-0,21 \mathrm{~mm}$ \\
\hline 4. & \multicolumn{2}{|c|}{ Bobot kapsul } & $74,2 \mathrm{~g}$ & $74,6 \mathrm{~g}$ & $57 \mathrm{~g}-69 \mathrm{~g}$ \\
\hline 5. & \multicolumn{2}{|c|}{ Volume } & $0,32 \mathrm{~mL}$ & $0,3 \mathrm{~mL}$ & $0,37 \mathrm{~mL}$ \\
\hline 6. & \multicolumn{2}{|c|}{ Kadar air } & $12,5 \%$ & $22 \%$ & $13 \%-16 \%$ \\
\hline 7. & \multicolumn{2}{|c|}{ Kelarutan dalam air } & 6 menit & 6,55 menit & $<15$ menit \\
\hline 8. & \multicolumn{2}{|c|}{ Kelarutan dalam asam } & 4,43 menit & 3,22 menit & $<5$ menit \\
\hline 9. & \multicolumn{2}{|c|}{ Kerapuhan } & Rapuh & Tidak rapuh & $\begin{array}{l}\text { Hancur dan retak } \\
\text { dikatakan rapuh }\end{array}$ \\
\hline
\end{tabular}


Pada proses pembuatan cangkang kapsul masih dilakukan secara manual yang menyebabkan cangkang kapsul yang didapatkan tidak merata. Pengukuran dimensi cangkang kapsul (Panjang, Diameter, Ketebalan, Volume dan Bobot kapsul) menggunakan 15 buah sampel.

Kadar air berhubungan erat dengan proses pengeringan kapsul jika kadar airnya tinggi kapsul akan menjadi lebih lunak dan jika kadar airnya kurang maka kapsul akan rapuh. Pengujian kadar air menggunakan oven dengan suhu $105^{\circ} \mathrm{C}$ selama 17 jam dan menggunakan alumunium dish yang bobotnya sudah konstan. Hasil yang diperoleh menunjukan kadar air formula I sebesar 12,5\%, hasil tersebut lebih rendah dari persyaratan yang ditetapkan, namun kadar air pada formula II cukup tinggi yaitu $22 \%$. Kadar air yang tinggi dapat disebabkan karena waktu pengeringan cangkang kapsul kurang.

Uji kelarutan dalam air atau disebut juga dengan uji disintegrasi dilakukan untuk mengukur seberapa cepat kapsul hancur menjadi agregat atau partikel lebih halus Alat yang digunakan adalah disintegration tester menggunakan aquadest sebagai media sebanyak $600 \mathrm{~mL}$ suhu $37^{\circ} \mathrm{C}$. Suhu ini digunakan karena dianggap sama dengan suhu tubuh manusia. Hasil uji disintegrasi dari kedua formula memenuhi persyaratan yang ditetapkan yaitu 6 menit dan 6,55 menit karena waktu yang diperlukan untuk menghancurkan kelima kapsul tidak boleh lebih dari 15 menit. [9]

Tujuan dari pengujian waktu hancur dalam asam adalah untuk memberi indikasi waktu yang dibutuhkan kapsul untuk larut dalam larutan lambung (Ridgway, 1987). pengujian media yang digunakan adalah $\mathrm{HCl} 0,1 \mathrm{~N}$ suhu $37^{\circ} \mathrm{C}$ suhu yang sesuai dengan suhu tubuh manusia. Hasil yang didapatkan dari dua formulasi adalah 4,43 menit dan 3,22 menit. Hasil tersebut memuhi persyaratan yaitu kurang dari 5 menit. [10]

Uji kerapuhan ini bertujuan untuk mengetahui ketahanan kapsul terhadap tekanan dari luar. Kerapuhan dipengaruhi oleh kadar air pada kapsul. Pengujian dilakukan dengan menggunakan gelas ukur berukuran $50 \mathrm{ml}$ berbahan dasar plastik kemudian kapsul dimasukan dan diberi beban 50 g. Hasil yang didapatkan menunjukan formula 1 cangkang kapsul tergolong rapuh karena pada saat diberikan beban cangkang kapsul menjadi hancur, hal tersebut sesuai dengan jumlah kadar air yang didapatkan untuk formula 1 dimana kadar airnya rendah $12 \%$. Pada formula 2 memenuhi syarat uji kerapuhan karena pada saat diberikan beban kapsul tidak hancur, hal ini disebabkan karena kadar air dalam formula 2 lebih tinggi yaitu sebesar $22 \%$.

\section{SIMPULAN}

1. Pembuatan gelatin yang bersumber dari tulang ikan lele dumbo (Clarias gariepinus) dapat dilakukan menggunakan cara asam dan larutan yang digunakan adalah $\mathrm{HCl}$.

2. Hasil pengujian gelatin menunjukan spesifikasi yang lebih rendah dari persyaratan yang ditetapkan. Spesifikasi tersebut meliputi $\mathrm{pH}$ gelatin 4,85, kadar air 13,5 \%, viskositas 180-190 Cps, kadar abu $3,2 \%$ dan kekuatan gel $150 \mathrm{~g} / \mathrm{cm}^{2}$.

3. Perbandingan terbaik untuk pembuatan cangkang kapsul keras adalah 1:2 (gelatin:air)

\section{SARAN}

1. Perlu dilakukan optimasi pada proses pencucian dan ekstraksi agar hasil gelatin yang diperoleh sesuai dengan standar gelatin komersial.

2. Perlu dilakukan optimasi proses pembuatan cangkang kapsul keras.

\section{DAFTAR PUSTAKA}

[1] Agoes. 2013. Pengembangan Sediaan Farmasi. Edisi tiga. Bandung: ITB. Hal 316-317.

[2] Irwandi, J., et., al. 2009. Extraction and Characteristic of Gelatin From Different Marine Fish Species in Malaysia. International Food Research Journal 16: 381-389.

[3] Karim, A.A. dan Bhat. R. 2009. Fish gelatin: properties, challenges, and prospects as an alternative to mammalian gelatins. Jurnal. Food Hydrocolloids. 23:563-576.

[4] Grossman, S., dan Bergman, M. 1991. Process for The Production of Gelatin from Fish Skins. European Paten Aplication 0436266 A1.

[5] [DJPB] Direktorat Jendral Perikanan Budaya. 2013. Produksi Perikanan Budidaya2013.http://www.djpb.kkp.go.id /public/upload/statistic.tahunan/PRODU 
51 | Triyani Sumiati et, al., (Sintesis dan Karakterisasi Cangkang Kapsul Keras...)

KSI\%20PB\%202013.pdf. [21 Maret 2017]

[6] Prosedur Tetap Quality Control. 2013. PT. Kapsulindo Nusantara.

[7] Dahlia, D. 2004. Pembuatan dan Analisis Gelatin dari Tulang Ikan Kakap Putih (Lates calcarifer Bloch). [Skripsi] Jakarta: Universitas Pancasila. Hal 32-24.

[8] Rao, R.K.V., Pakhale, S.P., Sigh, S. 2003 .A Film Approach For The Stabilization of Gelatin Preparations Against CrossLinking. Departemen of Pharmacy. India: National Institute of Pharmaceutical Education and Research. Jurnal Pharmaceutical Technology. Hal: 56-63

[9] [Depkes RI] Departemen Kesehatan RI 1995. Farmakope Indonesia Edisi IV. Jakarta: Depkes RI. Hal 2-4.

[10] Federal Specification, Nomor : U-C$115 \mathrm{~b}$.

[11] Natalia, D. 2010. Pembuatan Cangkang Kapsul Alginat Yang Mengandung Pewarna Ponceau 4r Dan Pengujian SifatSifat Fisiknya. [Skripsi]. Medan: Universitas Sumatra Utara. Hal 26.

[12] Nutra Food Ingredients. Fish Gelatin, http://nutrafoodingredients.com/. Diakses tanggal 19 September 2017

[13] Standar Nasional Indonesia (SNI) 06.3735. 1995. Mutu dan Cara Uji Gelatin.Dewan Standarisasi Nasional. Jakarta.

[14] Perdani, M.P. 2017. Analisis Kualitas Gelatin pada Cangkang Kapsul. [Karya Tulis Ilmiah]. Depok: Akademi Kimia Analis Cakara Nusantara hal 15.

[15] Sudarmadji, S. 1995. Prosedur Analisa Bahan Makanan Pertanian Edisi Keempat. Penerbit Liberty,Yogyakarta.Hal 98.

[16] Wijaya, H. 2001. Pengaruh Konsentrasi Asam Asetat dan Lama Perendaman Kulit Ikan Pari (Trygon spp) pada Pembuatan Gelatin. [Skripsi]. Bogor: Fakultas
Perikanan dan Ilmu Kelautan.Institut Pertanian Bogor. Hal 35.

[17] Wahid, M.A.A. (2015) Pengaruh Lama Perendaman Dan Perbedaan Konsentrasi Etanol Terhadap Nilai Rendemen dan Sifat Fisiko - Kimia Gelatin Tulang Sapi. [Skripsi] Fakultas Peternakan, Makasar : Universitas Hasanudin. Hal 24. 